\title{
A NEW METHOD OF EPISTAXIS MANAGEMENT USING NASAL GEL: A SINGLE CENTER, RANDOMIZED CLINICAL TRIAL
}

\section{MEHDI TORABI ${ }^{*}$, AVA ROUGHANI ESFAHANI ${ }^{2}$, SHIVA MOEINADDINI ${ }^{3}$, MOHAMMAD REZA BANESHI ${ }^{4}$}

${ }^{1}$ Department of Emergency Medicine, Kerman University of Medical Sciences, Kerman, Iran. ${ }^{2}$ Department of Emergency Medicine, Kerman University of Medical Sciences, Kerman, Iran. ${ }^{3}$ Department of Emergency Medicine, Rafsanjan University of Medical Sciences, Kerman, Iran. ${ }^{4}$ Modeling in Health Research Center, Institute for Futures Studies in Health, Kerman University of Medical Sciences, Kerman, Iran. Email: Mtorabi1390@yahoo.com/me_torabi@kmu.ac.ir

Received: 08 September 2017, Revised and Accepted: 28 November 2017

\section{ABSTRACT}

Objective: Epistaxis is one of the common causes of patients' referral to the emergency departments. In the majority of cases, epistaxis is managed by traditional methods. We investigated the efficacy of nasal gel (NG) in comparison to anterior nasal packing (ANP) to stop mild-to-moderate anterior nasal bleeding.

Methods: In this prospective, randomized clinical trial, patients were divided into two groups of ANP (n=60) and NG ( $\mathrm{n}=40$ ). We determined and compared the efficacy of treatment (bleeding stop time and recurrence), patients' satisfaction at discharge (length of stay in the hospital, pain during the procedure, and procedural time), and safety (less side effects) in both groups.

Results: The procedural time $\leq 2$ min was observed in $90 \%$ and $58.33 \%$ of NG group and ANP group, respectively (p<0.001). Pain score during procedure $\leq 4$ and patients' satisfaction $\geq 7$ were, respectively, seen in $87.5 \%$ and $65 \%$ of NG group, but it was $43.33 \%$ and $41.7 \%$ in ANP group, respectively $(\mathrm{p}<0.001, \mathrm{p}=0.02)$. The side effects in ANP group were 35\%; however, no side effects were observed in NG group.

Conclusion: In the management of mild-to-moderate anterior nasal bleeding although NG efficacy is equivalent to ANP, using NG may be more convenient and satisfactory for patients. In addition, the use of this gel may result in more safety and fewer side effects.

Keywords: Epistaxis, Patient satisfaction, Visual analog scale.

(c) 2018 The Authors. Published by Innovare Academic Sciences Pvt Ltd. This is an open access article under the CC BY license (http://creativecommons. org/licenses/by/4. 0/) DOI: http://dx.doi.org/10.22159/ajpcr.2018.v11i3.22462

\section{INTRODUCTION}

Epistaxis is the second cause of patients' referral with Ear, Nose, and Throat (ENT) problems to the emergency departments (ED) and nearly $60 \%$ of people experience epistaxis during their life cycle. Epistaxis has two age peaks $(<10$ and $>60$ years), two origins (anterior and posterior), and two types of primary ( $70-80 \%$ with no cause) and secondary (due to underlying diseases and anticoagulant medicines) $[1,2]$. Evidence shows that epistaxis in most cases is self-limiting, but it can be life-threatening, especially in elderly with underlying diseases [3].

Today, on account of using anticoagulant drugs, the prevalence of epistaxis is on a rise [4]. However, therapeutic strategies are very different, and no defined guideline exists in epistaxis management $[5,6]$. A preferable procedure to control bleeding is nasal endoscopy, but since it is not available in all centers, nasal packing is still the most common applied technique [7]. This mechanical treatment causes some problems. Low-risk side effects such as pain and discomfort to high-risk side effects such as toxic shock syndrome can occur. This is inevitable as the nasal mucosa is a common site for infection and hospital environment, as well as devices, are often resistant to disinfectants [5-9]. Furthermore, in most hospitals, nasal bleeding control is done by general physicians who might not have the expertise to do this procedure [10]. Besides this traditional mechanical technique, the use of more convenient local medicines such as pig thrombin (floseal) and herbal drugs are increasing [11-14]. One of these convenient methods is using nasal gel (NG). Nozohaem for epistaxis treatment is easy and has the fast effect. This gel increases vasoconstriction in the nasal mucosa and activates coagulation system. Platelets aggregation to collagen forms a plug. Then, fibrin threads and clots are made. This gel contains glycine and calcium (www.nozohaem. com). Glycine is an amino acid which is used in the production of protein and collagen. Collagen causes efficient platelets function to decrease bleeding. Glycine helps to control bleeding through absorbing water and increasing the concentrations of coagulant factors and platelets [15]. Meantime, calcium promotes coagulation through inducing coagulation process and activating coagulant factors such as factor 13 [16]. In addition, platelets induce the process of clot repair by increasing calcium $[17,18]$.

The aim of this study was to compare NG with anterior nasal packing (ANP) in mild-to-moderate anterior nasal bleeding management. The primary outcome was NG efficacy (bleeding stop time and recurrence). The secondary outcomes were patients' satisfaction at discharge (length of stay in the hospital, pain during the procedure, and procedural time) and safety (less side effects) of using NG.

\section{METHODS}

Study period

The study was conducted over a period of $6 \mathrm{~m}$ from November 2015 to April 2016.

\section{Study design}

This prospective, randomized clinical trial was performed on patients with anterior nasal bleeding referred to Shafa Hospital in Kerman. Shafa hospital is the referral center for ENT patients in the southeast of Iran. In this study, the efficacy and safety of ANP and NG procedures, and patients' satisfaction in these two groups were compared with each other. Treatment procedures were done by a trained general physician, and data were gathered by an emergency medicine 
specialist. Another emergency medicine specialist supervised data collection.

\section{Ethics committee approval}

The study was approved by the Ethical Committee of Kerman University of Medical Sciences and also Iranian registry of clinical trials (Irct ID: IRCT 2016121222181N2). Oral consent was obtained from each patient.

\section{Patient data collection form}

The patients were selected randomly from those who presented to the ED with epistaxis. At first, the patients were examined by a trained general physician. Medication allocation was done based on simple random sampling, and the patients were allocated randomly to one of the two mentioned treatment approaches. Random codes were obtained by SPSS software. Both treatment procedures were performed by the same trained general physician, and data gathering was done by an emergency medicine specialist. Considering the different nature of the two procedures, emergency medicine specialists, and the general physician were not blinded to the study.

\section{Plan of work}

A total of 100 patients were randomized (60 patients underwent ANP, and 40 patients received NG). In the ANP group, first, a cotton ball, previously soaked in a mixture of 2\% lidocaine and 1:100 000 epinephrine, was placed in the anterior nostril after clearing of the clots by nasal blowing. The emergency medicine specialist examined the patients every 2 min until the bleeding stoppage. Finally, the nose was packed with tetracycline-impregnated gauze. The nasal pack was removed after 2-3 days. All nasal packing procedures were performed by the same trained general physician. In the second group, after blowing the nose, the trained physician entered NG tube (Fig. 1) into the patient's nose about $1-1.5 \mathrm{~cm}$ and emptied the contents of tube ( $2 \mathrm{ml}$ gel) with fast pressure while getting the nose with thumb and point fingers. In the case of bleeding continuation, the second tube was used. Concerning no response to the treatment in the ANP group, chemical cauterization with silver nitrate and in the NG group, ANP was used. In resistant to treatment, bilateral nasal packing was performed.

During and after the intervention, the patients were evaluated every 2 min to determine bleeding stop time. After the bleeding stopped, the designed questionnaire was completed by an emergency medicine specialist. The variables including bleeding severity grading to exclude severe nasal bleeding [19], bleeding stop time after the intervention, pain score during the procedure and patient's satisfaction at discharge

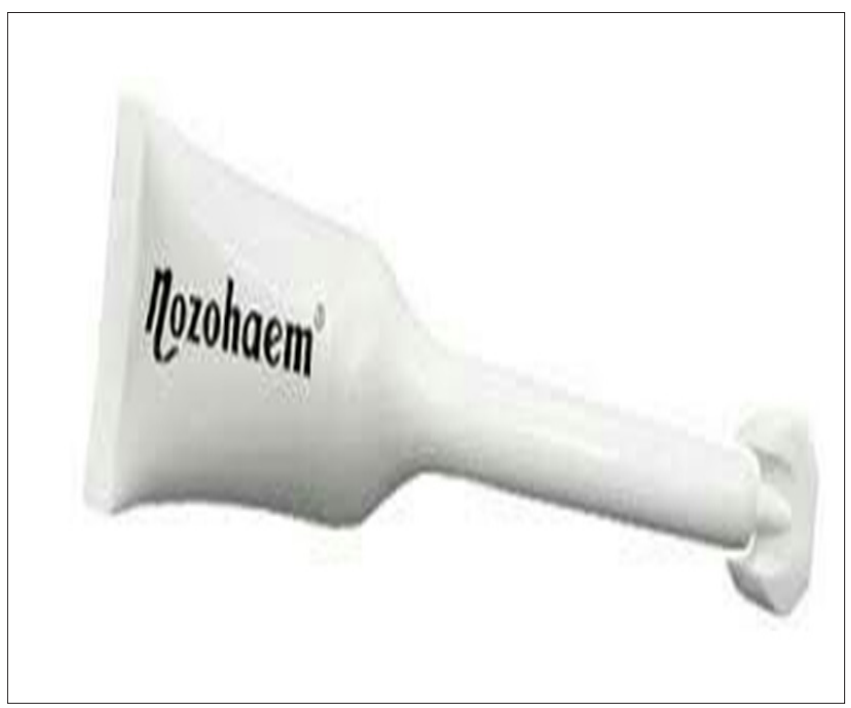

Fig. 1: Nasal gel tube using visual analog scale (VAS) [20,21], discharge time, procedural time, and side effects in each group were determined and compared. Bleeding recurrence in patients ( $24 \mathrm{~h}$ and 1 week after discharge) was followed up by telephone.

\section{Inclusion and exclusion criteria}

The patients with mild-to-moderate anterior nasal bleeding were enrolled into the study. We excluded other epistaxis patients. From 146 patients, 100 patients were selected and divided randomly into two groups of ANP ( $n=60)$ and NG $(n=40)$ (Fig. 2).

\section{Sample size calculation}

This was a parallel-group randomized controlled trial. In $30 \%$ of patients with epistaxis treated with ANP, the bleeding stopped $<8 \mathrm{~min}$ [2]. In the current study, we aimed whether a new treatment (NG) could achieve $60 \%$ success $(\Delta=30 \%)$. We set 2 -sided $\alpha$ of 0.05 and power of $80 \%$, and sample size in each group was calculated to be 40 according to the formula (80 in total) [22].

$\mathrm{n}=\frac{\left[\mathrm{Z} 1-\frac{ \pm}{2} \sqrt{2 \overline{\mathrm{P}}(1-\overline{\mathrm{P}})}+\mathrm{Z} 1-\beta \sqrt{\mathrm{P} 0(1-\mathrm{P} 0)+\mathrm{P} 1(1-\mathrm{P} 1)}\right]^{2}}{(\mathrm{P} 1-\mathrm{P} 0)^{2}}=40$

During the study period, 20 more patients were referred to the hospital. Therefore, in total 100 patients were enrolled.

\section{Statistical analysis}

Data analysis was done through IBM SPSS statistics version 20 using independent-sample $t$-test and $\chi^{2}$ to compare basal characteristics between the two groups. Efficacy of interventions was evaluated using $\chi^{2}$ test. Results are presented in terms of odds ratio (OR) (95\% confidence interval $[\mathrm{CI}])$.

\section{RESULTS}

A total of 100 patients were recruited in this study, 51 patients were male, and 49 were female. The mean \pm standard deviation age was $43.63 \pm 20.78$ and $39.48 \pm 19.03$ in ANP and NG groups, respectively. As contrary to sex, there was no significant difference between the two groups concerning age, history of epistaxis, history of anticoagulants consumption, underlying diseases, and the results of prothrombin time and platelet count (Table 1).

NG group was superior to ANP treatments in terms of almost all outcomes. The procedural time $\leq 2 \mathrm{~min}$ was observed in 36 patients (90\%) of NG group and 35 patients (58.33\%) of ANP group (OR, 0.15; 95\% CI 0.04-0.92, $\mathrm{p}<0.001$ ). This indicates that those in ANP group were $85 \%$ less likely to experience procedural duration of $\leq 2 \mathrm{~min}$. The bleeding stop time $\geq 8$ min was less in the ANP group compared to the NG group ( $50 \%$ vs. $67.5 \%$ ), which was of marginal significance ( $p=0.08)$. In addition, discharge time $\leq 55$ min was higher in the NG group $(62.5 \%$ vs. $43.33 \%$ ) giving a $\mathrm{p}=0.06$. Pain score during procedure $\leq 4$, determined based on VAS, was observed in $87.5 \%$ of NG group and $43.33 \%$ of ANP

Table 1: Patient characteristics

\begin{tabular}{|c|c|c|c|}
\hline Group & ANP1 & $N G^{2}$ & $\mathbf{p}$ \\
\hline Age (mean $\pm S D)$ & $43.63 \pm 20.78$ & $39.48 \pm 19.03$ & 0.54 \\
\hline Sex (\%) (male/female) & $58.33 / 41.67$ & $35.00 / 65.00$ & 0.02 \\
\hline History of epistaxis (\% of yes) & 61.67 & 70.00 & 0.39 \\
\hline History of anticoagulant ( $\%$ of yes) & 38.33 & 35.00 & 0.73 \\
\hline Underlying disease ( $\%$ of yes) & 37.29 & 52.50 & 0.13 \\
\hline $\mathrm{PLT}^{3} \times 10^{3} / \mu \mathrm{l}(\mathrm{mean} \pm \mathrm{SD})$ & $287.70 \pm 40.31$ & $275.14 \pm 40.4$ & 0.22 \\
\hline $\mathrm{PT}^{4}(\mathrm{~s})$ & $11.94 \pm 1.89$ & $12.51 \pm 0.70$ & 0.14 \\
\hline Intensity of bleeding (\%) & $43.33 / 56.67$ & $70.00 / 30.00$ & \\
\hline
\end{tabular}

${ }^{1}$ Anterior nasal packing $(n=60),{ }^{2}$ nasal gel $(n=40),{ }^{3}$ Platelet, ${ }^{4}$ Prothrombin time. SD: Standard deviation 


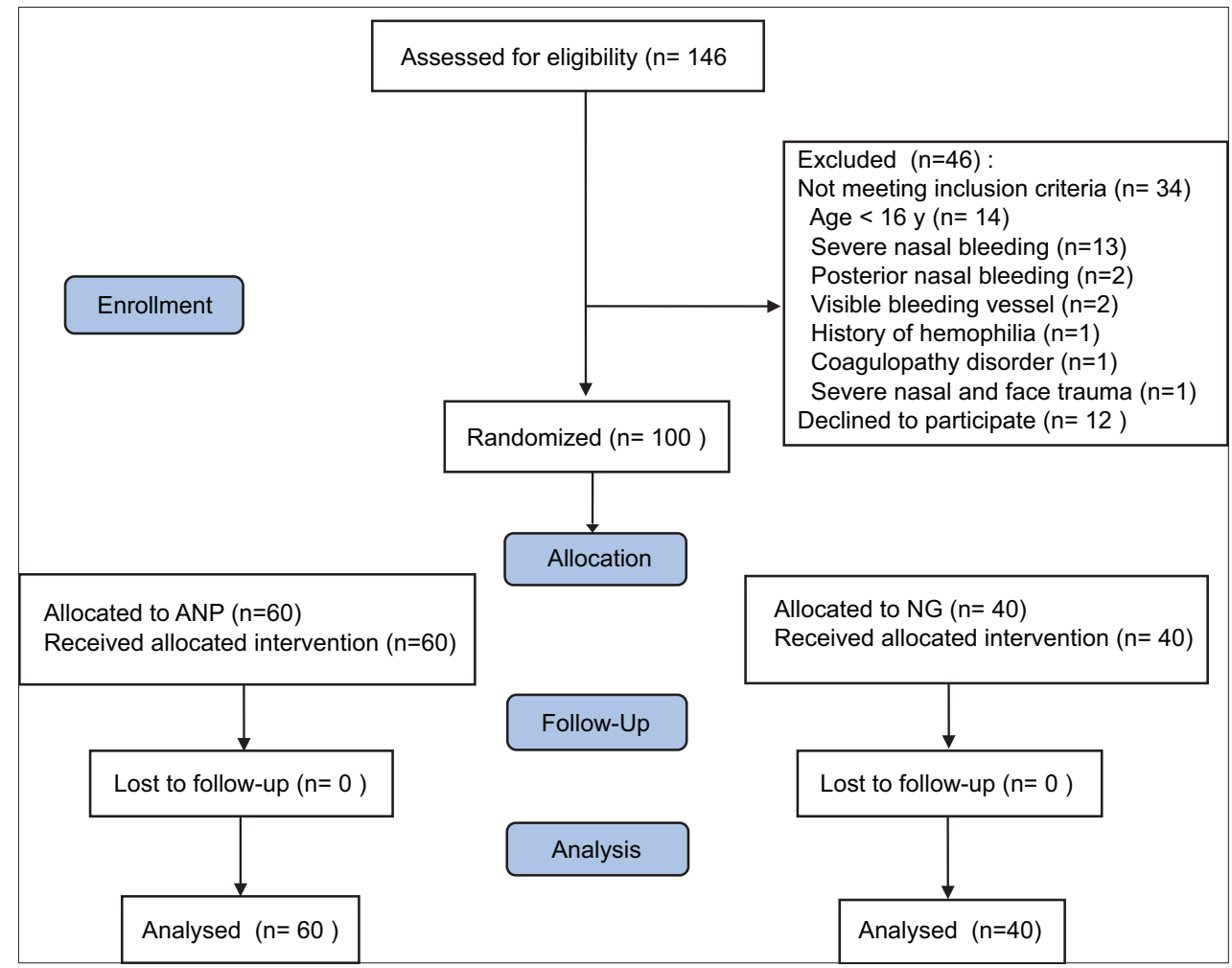

Fig. 2: Consolidated Standards of reporting trials flow diagram

group (OR, 0.1; 95\% CI, 0.30-0.31, $\mathrm{p}<0.001$ ). This indicates that those in ANP group were $90 \%$ less likely to have pain score $\leq 4$. While $41.7 \%$ of ANP patients were satisfied, corresponding figure in NG group was $65 \%$, (OR, 0.38; 95\% CI, 0.16-0.88, p=0.02). In regard to the observed side effects (nausea, intolerance), it was 35\% in ANP group, but no side effects were observed in NG group. ANP group was only better than NG in terms of recurrence. In the NG group, $25 \%$ of patients experienced the recurrence. Corresponding figure in the ANP group was about $12 \%$ $(\mathrm{OR}=0.40, \mathrm{p}=0.08)$ (Table 2).

\section{DISCUSSION}

Although ANP, as a mechanical procedure, is still a common procedure in the management of epistaxis, there are more convenient procedures for this purpose. Since there was no significant difference in bleeding stop time and recurrence in NG and ANP groups, this study showed similar efficacy for both procedures in epistaxis treatment. There was no significant difference in discharge time in both groups; however, pain during the procedure and procedural time were lower in NG group compared to ANP group. In addition, patients' satisfaction at discharge was higher in NG group. The safety use of NG was more than ANP due to fewer side effects.

There are several medical procedures for epistaxis management. Different anticoagulants and vasoconstrictors medicines have shown more effective in comparison to mechanical procedures in the control of anterior and even posterior nasal bleeding $[12,13,23,24]$. Some medicines, such as bismuth, in combination with other and even some herbal medicines, have shown good efficiency in bleeding control $[25,26]$. In the absence of severe bleeding and high-risk conditions, local medical treatments are preferable in comparison to surgical procedures [12], unless no response to them is seen [27-29]. These methods are a better tolerated, more safe, and easy alternative to nasal packing in patients presenting with acute anterior epistaxis $[12,23,24]$. In the present study, there was no significant difference in bleeding stop time between NG and ANP procedure, in regard to their efficiency in the control of mild-to-moderate anterior nasal bleeding (Grades I and II). This can be due to good NG efficacy in
Table 2: Effect of ANP compared with NG on efficacy variables

\begin{tabular}{|c|c|c|c|c|}
\hline Group & ANP $^{1}$ & $N G^{2}$ & OR $(95 \% \mathrm{CI})$ & $\mathbf{p}$ \\
\hline $\begin{array}{l}\text { Procedural time } \\
\leq 2 \min (\%)\end{array}$ & 58.33 & 90.00 & $0.15(0.04-0.49)$ & $<0.001$ \\
\hline $\begin{array}{l}\text { Bleeding stop time } \\
\geq 8 \min (\%)\end{array}$ & 50.00 & 67.50 & $0.48(0.20-1.10)$ & 0.08 \\
\hline $\begin{array}{l}\text { Discharge time } \\
\leq 55 \min (\%)\end{array}$ & 43.33 & 62.50 & $0.45(0.20-1.04)$ & 0.06 \\
\hline $\begin{array}{l}\mathrm{VAS}^{3} \text { of pain during } \\
\text { procedure } \leq 4(\%)\end{array}$ & 43.33 & 87.50 & $0.1(0.03-0.31)$ & 0.001 \\
\hline $\begin{array}{l}\text { VAS of satisfaction } \\
\geq 7(\%)\end{array}$ & 41.70 & 65.00 & $0.38(0.16-0.88)$ & 0.022 \\
\hline $\begin{array}{l}\text { Side effects in the } \\
\text { ED (\%) }\end{array}$ & 35.00 & 0 & & \\
\hline Recurrence (\%) & 11.67 & 25.00 & $0.40(0.14-1.15)$ & 0.08 \\
\hline
\end{tabular}

controlling Grades I and II epistaxis through reabsorption of water and concentrating coagulation factors and platelets in the bleeding site. In addition, the two studied groups indicated no significant difference in bleeding recurrence during the first $24 \mathrm{~h}$ and the $1^{\text {st }}$ week after the intervention. However, the underlying conditions in the two groups were not significantly different. Therefore, the efficacy of this method in epistaxis control including bleeding stop time and recurrence is similar to ANP and may be of considerable importance, although there is little evidence of the effectiveness of this gel.

Patients' satisfaction is a pivotal factor concerning hospital service quality. Patients are too expectant about the quality and speed of received treatments in the ED. Several factors affect patients' satisfaction in the ED. Among these factors, pain control has a role regarding the satisfaction rate [30-32]. In our study, use of NG caused significantly increased patients' satisfaction. In addition, there are several supportive medications to control epistaxis in spite of various invasive surgical 
procedures $[13,14,33]$. These nonsurgical procedures are preferred to control mild-to-moderate bleedings [27]. Using these methods, due to their convenience and less pain, are increasing in comparison to painful surgical methods and chemical cauterization [6]. In the present study, NG group showed lower pain during the procedure and higher patients' satisfaction in comparison to ANP group. In nasal packing, as a traumatic, painful procedure, both insertion and removal of the packs are painful and cause great suffering. Moreover, it needs a second refers to the hospital for pack removal while NG, after being swallowed, is easily exerted through the digestive system. However, it is important that the use of either of these procedures should be according to the physician opinion or even patient's preference. Moreover, due to the overcrowding conditions in the ED and its outcomes, short hospital stay and early discharge are very significant [34]. In our study, two groups showed no significant difference in this term that can be attributed to the small sample size; however, procedural time in NG group was significantly shorter. This time-saving procedure could result in more satisfaction and improved ED management. In this study, pain score during the procedure and procedural time were lower in NG group that cause patients' satisfaction at discharge.

The mechanical procedure of nasal packing has some side effects which compromise patients' health. This technique can cause some problems such as pain and discomfort, septum necrosis, local infection, toxic shock syndrome, and the need for using antibiotics or analgesics. Some of these can cause irreversible and dangerous side effects $[5,6]$. Although in this study, all these side effects were not seen in the hospital or patients' follow up, some side effects such as intolerance and nausea were significantly more in ANP group. Therefore, NG using has more safety and fewer side effects.

In our randomization process, we used a random number generator to divide subjects into two groups. This method does not guarantee the matching of baseline characteristics and potential confounders between two arms. In addition, the sample size at two arms might be different. However, here, fortunately, distribution of almost all baseline characteristics was the same in the two groups. In future studies, we recommend using better randomization methods such as minimization.

\section{Limitations}

The present study had the following limitations: The sample size was small due to the lack of access to NG, patients with severe (Grade III) or posterior nasal bleeding and those younger than 16 years were excluded, and the study subjects were selected from only one center. None of the patients and general physician and emergency medicine specialists were blinded to the study.

\section{CONCLUSION}

It seems that use of NG can be safe and efficient in mild-to-moderate anterior epistaxis management. Increasing patients' satisfaction resulting from less pain during the procedure, shorter procedural time, and fewer side effects are some of the desirable characteristics of this procedure in comparison to ANP. Due to the small sample size, another study is recommended with a larger sample size. In particular, there is little evidence of the benefits and effectiveness of this gel.

\section{AUTHORS CONTRIBUTION}

Study concept, design and supervision: MT; acquisition of data: AR and SHM; analysis and interpretation of data: MRB; drafting of the manuscript, technical and material support: MT.

\section{FUNDING/SUPPORT}

This study was sponsored by Kerman University of Medical Sciences.

\section{CONFLICTS OF INTERESTS}

None declared.

\section{REFERENCES}

1. Spielmann PM, Barnes ML, White PS. Controversies in the specialist management of adult epistaxis: An evidence-based review. Clin Otolaryngol 2012;37:382-9.

2. Zahed R, Moharamzadeh P, Alizadeharasi S, Ghasemi A, Saeedi M. A new and rapid method for epistaxis treatment using injectable form of tranexamic acid topically: A randomized controlled trial. Am J Emerg Med 2013;31:1389-92.

3. Strand M, Meyers J, Boyer H. Epistaxis in a patient on antiplatelet therapy: Not always benign. Am J Otolaryngol 2014;35:411-3

4. Singer AJ, Blanda M, Cronin K, LoGiudice-Khwaja M, Gulla J, Bradshaw J, et al. Comparison of nasal tampons for the treatment of epistaxis in the emergency department: A randomized controlled trial. Ann Emerg Med 2005;45:134-9.

5. Barnes ML, Spielmann PM, White PS. Epistaxis: A contemporary evidence based approach. Otolaryngol Clin North Am 2012;45:1005-17

6. Chhapola S, Matta I, Marker P. Comparison of blind nasal packing vs endoscopic Control of epistaxis in an emergency setting. Int J Head Neck Surg 2012;2:79-82.

7. Cohn B. Are prophylactic antibiotics necessary for anterior nasal packing in epistaxis? Ann Emerg Med 2015;65:109-11.

8. Kashyap S. Influence of topical retapamulin (1\%) ointment, sofinox-rd cream, sofinox cream $(2 \%)$, zinc fusidate cream $(2 \%)$ and zinc fusidate ointment $(2 \%)$ on nasal mucosal surface safety in new zealand albino rabbits. Int J Pharm Pharm Sci 2015;7:183-6.

9. Wadhwa R, Sharma Y, Upadhyay RP, Bala K. Nosocomial infection by non-fermenting gram negative bacilli in tertiary care hospital: Screening and cure. Int J Pharm Pharm Sci 2016;8:274-7.

10. Murthy P, Nilssen EL, Rao S, McClymont LG. A randomised clinical trial of antiseptic nasal carrier cream and silver nitrate cautery in the treatment of recurrent anterior epistaxis. Clin Otolaryngol Allied Sci 1999;24:228-31.

11. Mudunuri RK, Murthy MA. The treatment of spontaneous epistaxis: Conservative vs cautery. J Clin Diagn Res 2012;6:1523.

12. Mathiasen RA, Cruz RM. Prospective, randomized, controlled clinical trial of a novel matrix hemostatic sealant in patients with acute anterior epistaxis. Laryngoscope 2005;115:899-902.

13. Meric Teker A, Korkut AY, Kahya V, Gedikli O. Prospective, randomized, controlled clinical trial of ankaferd blood stopper in patients with acute anterior epistaxis. Eur Arch Otorhinolaryngol 2010;267:1377-81

14. Stieler M, Weber J, Hils M, Kolb P, Heine A, Büchold C, et al. Structure of active coagulation factor XIII triggered by calcium binding: Basis for the design of next-generation anticoagulants. Angew Chem Int Ed Engl 2013;52:11930-4

15. Heemskerk JW, Mattheij NJ, Cosemans JM. Platelet-based coagulation: Different populations, different functions. J Thromb Haemost 2013;11:2-16

16. Xu X, Teng X. Effect of fibrinogen on blood coagulation detected by optical coherence tomography. Phys Med Biol 2015;60:4185-95.

17. Foley JH, Butenas S, Mann KG, Brummel-Ziedins KE. Measuring the mechanical properties of blood clots formed via the tissue factor pathway of coagulation. Anal Biochem 2012;422:46-51

18. Milojevic K, Cantineau JP, Simon L, Bataille S, Ruiz R, Coudert B, et al. Acute severe pain in emergencies. The key for efficient analgesia. Ann Fr Anesth Reanim 2001;20:745-51.

19. Walker TW, Macfarlane TV, McGarry GW. The epidemiology and chronobiology of epistaxis: An investigation of Scottish hospital admissions 1995-2004. Clin Otolaryngol 2007;32:361-5.

20. Singer AJ, Thode HC Jr. Determination of the minimal clinically significant difference on a patient visual analog satisfaction scale. Acad Emerg Med 1998;5:1007-11

21. Collins SL, Moore RA, McQuay HJ. The visual analogue pain intensity scale: What is moderate pain in millimeters? Pain 1997;72:95-7.

22. Daly LE, Bourke GJ. Interpretation and Uses of Medical Statistics. $5^{\text {th }}$ ed. Oxford: Blackwell Science Ltd.; 2000.

23. Tibbelin A, Aust R, Bende M, Holgersson M, Petruson B, Rundcrantz $\mathrm{H}$, et al. Effect of local tranexamic acid gel in the treatment of epistaxis. ORL J Otorhinolaryngol Relat Spec 1995;57:207-9.

24. Kilty SJ, Al-Hajry M, Al-Mutairi D, Bonaparte JP, Duval M, Hwang E, et al. Prospective clinical trial of gelatin-thrombin matrix as first line treatment of posterior epistaxis. Laryngoscope 2014;124:38-42

25. Binder JE. Inventor; Binyarco, Llc, Assignee. Composition and Method 
for Treating Nosebleeds. 2016. United States Patent Application No. 9 , 248,186 .

26. Corbridge RJ, Djazaeri B, Hellier WP, Hadley J. A prospective randomized controlled trial comparing the use of merocel nasal tampons and BIPP in the control of acute epistaxis. Clin Otolaryngol Allied Sci 1995;20:305-7.

27. Soyka MB, Nikolaou G, Rufibach K, Holzmann D. On the effectiveness of treatment options in epistaxis: An analysis of 678 interventions. Rhinology 2011;49:474-8.

28. Klossek JM, Dufour X, de Montreuil CB, Fontanel JP, Peynègre R, Reyt $\mathrm{E}$, et al. Epistaxis and its management: An observational pilot study carried out in 23 hospital centres in France. Rhinology 2006;44:151-5.

29. Al-Deen S, Bachmann-Harildstad G. A grading scale for epistaxis in hereditary haemorrhagic teleangectasia. Rhinology 2008;46:281-4.

30. Bhakta HC, Marco CA. Pain management: Association with patient satisfaction among emergency department patients. J Emerg Med 2014;46:456-64.

31. Tekwani KL, Kerem Y, Mistry CD, Sayger BM, Kulstad EB. Emergency department crowding is associated with reduced satisfaction scores in patients discharged from the emergency department. West J Emerg Med 2013;14:11-5

32. Boudreaux ED, O'Hea EL. Patient satisfaction in the emergency department: A review of the literature and implications for practice. J Emerg Med 2004;26:13-26.

33. Badran K, Malik TH, Belloso A, Timms MS. Randomized controlled trial comparing Merocel ${ }^{\circledR}$ and RapidRhino ${ }^{\circledR}$ packing in the management of anterior epistaxis. Clin Otolaryngol 2005;30:333-7.

34. Santos E, Cardoso D, Queirós P, Cunha M, Rodrigues M, Apóstolo J, et al. The effects of emergency department overcrowding on admitted patient outcomes: A systematic review protocol. JBI Database System Rev Implement Rep 2016;14:96-102. 